\title{
Avaliação da exposição solar na intoxicação experimental por Brachiaria decumbens em ovinos ${ }^{1}$
}

\author{
Mirna R. Porto은 Klaus C. Saturnino ${ }^{3}$, Eduardo M.M. Lima², Stephen T. Lee ${ }^{4}$, Ricardo A.A. \\ Lemos $^{5}$, Clairton Marcolongo-Pereira ${ }^{6}$, Franklin Riet-Correa ${ }^{7}$ e Márcio B. de Castro ${ }^{2 *}$
}

\begin{abstract}
Porto M.R., Saturnino K.C., Lima E.M.M., Lee S.T., Lemos R.A.A., Marcolongo-Pereira C., Riet-Correa F. \& Castro M.B. 2013. [Evaluation of solar exposure in Brachiaria decumbens poisoning in sheep.] Avaliação da exposição solar na intoxicação por $B r a-$ charia decumbens em ovinos. Pesquisa Veterinária Brasileira 33(8):1009-1015. Laboratório de Patologia Veterinária, Hospital Veterinário, Universidade de Brasília, Via L4 Norte, Cx. Postal 4508, Brasília, DF 70910-970, Brazil. E-mail: mbcastro@unb.br

Twenty-six five-month-old lambs originated from flocks with no previous contact with Brachiaria spp. pastures were divided into three groups. Two groups (GS and GSB) were fed daily with fresh harvested Brachiaria decumbens ad libitum. GS was kept in an area with solar exposure and GSB was kept in stalls sheltered from solar exposure. Control group (GC) was also kept under solar exposure, but fed with Cynodon dactylon grass hay and Pennisetum purpureum fresh grass. All sheep from the three groups were supplemented with $200 \mathrm{~g}$ daily of a commercial concentrated food. Evaluation of clinical signs was carried out daily and blood samples were collected twice a week to determine AST and GGT serum activities. Three out of nine lambs of GS presented clinical signs of Brachiaria spp. poisoning, and two died. One animal showed clinical signs and died in GSB. The main clinical signs observed were apathy, weight loss, photophobia, conjunctivitis, ocular mucous discharge and jaundice. Dermatitis due to photosensitization was not observed. Mean serum AST and GGT activities were significantly higher $(p \leq 0,05)$ in the group exposed to sun, than in the other two groups, and the GGT activities were significantly higher in the group sheltered than in the control group $(p \leq 0,05)$. All animals at the end of the experiment were submitted to liver biopsy and died lambs were necropsied. Histopathological evaluation of liver samples from sheep with clinical signs evidenced swelling and vacuolization of hepatocytes, individual hepatocytes necrosis, presence of foamy macrophages, crystal negative images within bile ducts and foamy macrophages, biliary duct hyperplasia and periportal mononuclear infiltration. These results suggest that sun exposure does not define intoxication, but exacerbates the toxicity of the grass.
\end{abstract}

INDEX TERMS: Poisonous plants, Brachiaria spp., plant poisoning, photosensitization, sheep.

\footnotetext{
${ }^{1}$ Recebido em 17 de julho de 2013.

Aceito para publicação em 12 de agosto de 2013.

${ }^{2}$ Hospital Veterinário, Universidade de Brasília (UnB), Via L4 Norte, Cx. Postal 4508, Brasília, DF 70910-970, Brasil. *Autor para correspondência: mbcastro@unb.br

${ }^{3}$ Universidade Federal de Rondônia, Rolim de Moura, R0 76940-000, Brasil.

${ }^{4}$ Poisonous Plant Research Laboratory, Agricultural Research Service, United States Department of Agriculture, 1150 E. 1400 N., Logan, Utah 84341, USA.

${ }^{5}$ Faculdade de Medicina Veterinária e Zootecnia, Universidade Federal de Mato Grosso do Sul, Campo Grande, MS 79070-900, Brasil.

${ }^{6}$ Pós-Graduando em Medicina Veterinária, Faculdade de Veterinária, Universidade Federal de Pelotas (UFPel), Campus Universitário s/n, Pelotas, RS 96010-900, Brasil.

${ }^{7}$ Hospital Veterinário, Universidade Federal de Campina Grande, Patos, PB 58700-000, Brasil.
}

RESUMO.- Foram utilizados 26 ovinos, entre 3 e 4 meses de idade, divididos em 3 grupos, provenientes de rebanhos que nunca tiveram contato com pastos de Brachiaria spp.. Dois grupos receberam Brachiaria decumbens no cocho diariamente ad libitum, sendo que um deles permaneceu em área com exposição solar (GS) e o outro foi mantido em baias cobertas protegidos do sol (GSB). 0 grupo controle (GC) foi também mantido em local com exposição solar e alimentado com feno de Cynodon dactylon e capim Pennisetum purpureum triturado. Todos os grupos receberam alimentação em cochos e foram suplementados com 200g/ dia/animal de ração comercial para ovinos. Foi realizada a avaliação clínica diária dos ovinos e colhidas amostras duas vezes por semana para dosagem sérica de AST e GGT. Os 
animais que morreram foram submetidos a necropsia e em todos os ovinos sobreviventes foi realizada biópsia hepática no final do experimento. Três animais do grupo GS adoeceram e dois morreram. Um ovino do grupo GSB adoeceu e morreu. Não houve alterações clínicas nos ovinos controles. Os principais sinais clínicos observados nos animais que adoeceram foram apatia, emagrecimento, fotofobia, hiperemia e secreção ocular e icterícia. Nenhum animal apresentou lesões cutâneas de fotossensibilização. 0 grupo que permaneceu no sol apresentou atividades séricas médias de AST e GGT significativamente maiores que a dos demais grupos $(\mathrm{p} \leq 0,05)$ e os animais que permaneceram na sombra apresentaram níveis maiores de GGT $(\mathrm{p} \leq 0,05)$ em comparação ao grupo controle. A histopatologia das amostras de fígados dos ovinos com sinais clínicos demonstrou tumefação e vacuolização de hepatócitos, necrose individual de hepatócitos, macrófagos espumosos com cristais birrefringentes intracitoplasmáticos e dentro de ductos biliares e infiltrado mononuclear periportal. Amostras do capim fornecidas aos cordeiros evidenciaram níveis médios de $0,94 \pm 0,80 \%$ da saponina protodioscina. As observações do presente experimento sugerem que a não exposição ao sol não evita a presença de sinais clínicos da intoxicação, mas que a exposição solar exacerba os sinais clínicos.

TERMOS DE INDEXAÇÃO: Plantas tóxicas, Brachiaria spp., intoxicação por plantas, fotossensibilização, ovinos.

\section{INTRODUÇÃO}

A intoxicação por braquiária é um dos maiores entraves à expansão da ovinocultura nacional nas áreas de Cerrado. Apesar de ser uma das principais forrageiras utilizadas na pecuária brasileira, provoca severas perdas nos rebanhos devido à perdas produtivas e morte de ovinos (Castro et al. 2011, Riet-Correa et al. 2011, Mustafa et al. 2012). Mesmo sendo de grande importância para a pecuária extensiva, Brachiaria spp. apresentam graus variáveis de toxicidade associada aos seus níveis de saponina (Riet-Correa et al. 2011). As protodioscinas são saponinas presentes na $\mathrm{Bra}$ chiaria decumbens, quando metabolizadas no trato digestório dos animais, dão origem às sapogeninas epismilagenina e episarsasapogenina (Sallam Abdullah et al. 1992, Cruz et al. 2000). As saponinas esteroidais litogêncicas presentes na forrageira causam, entre outras alterações, formação de material cristalóide em ductos biliares e interferência no metabolismo de hepatócitos (Graydon et al. 1991, Santos et al. 2008). Essas alterações promovem a obstrução dos ductos biliares, seguida de acúmulo de filoeritrina na circulação e nos tecidos, causando fotossensibilização (Abdhullah et al. 1992, Lajis et al. 1993, Cheeke 1995, Cruz et al. 2001, Stegelmeier 2002, Santos et al. 2008).

Dentre os principais sinais clínicos observados na intoxicação de ovinos pela braquiária, destaca-se a fotossensibilização, caracterizada por edema de face e orelhas, lesões eritematosas, com presença de crostas em regiões despigmentadas da pele ou desprovidas de pelos mais expostas ao sol (Lemos et al. 1996, Mendonça et al. 2008, Santos et al. 2008). Icterícia, fotofobia, apatia, diminuição do apetite e emagrecimento também são alterações descritas, e junto com a fotossensibilização, formam o conjunto dos sinais clínicos mais importantes para o diagnóstico da intoxicação (Tokarnia et al. 2012, Riet-Correa \& Mendez. 2007).

Mais recentemente foi descrita uma forma aguda da intoxicação em ovinos por braquiária, com sinais clínicos discretos ou praticamente ausentes. Os animais desenvolvem apatia, morrem e não apresentam lesões cutâneas de fotossensibilização nem icterícia (Santos Júnior 2008, Riet-Correa et al. 2011). Os mecanismos envolvidos na morte aguda desses ovinos intoxicados pela forrageira ainda são desconhecidos, mas há importantes indícios que sugerem tratar-se de alteração severa no metabolismo hepático (Castro et al. 2011).

A ação hepatotóxica das saponinas presentes na braquiária, não necessariamente promovem o surgimento de fotossensibilização nos animais doentes. Essa observação, até o momento, ainda não foi totalmente comprovada, sendo necessário determinar até que ponto a exposição solar nos ovinos realmente interfere no curso da intoxicação pela gramínea. 0 esclarecimento dessas questões são de grande importância prática, pois podem trazer mudanças na identificação das formas clínicas tradicionais da intoxicação por Brachiaria spp. nos animais.

\section{MATERIAL E MÉTODOS}

Foram utilizados 26 ovinos mestiços da raça Santa Inês, 13 machos e 13 fêmeas, com 3 a 4 meses de idade, provenientes de plantéis que nunca tiveram contato com pastos de Brachiaria spp. (animais não-adaptados ao pastejo na gramínea). Os cordeiros foram separados randomicamente em 3 grupos. 0 grupo controle (GC; $\mathrm{n=8}$ ) e o grupo sol (GS; n=9) foram mantidos em área descoberta contendo uma pequena casa de madeira, medindo $1,5 \times 2,0 \times 2,0 \mathrm{~m}$, para proteção de eventuais chuvas e abrigo noturno. Os ovinos do grupo sombra (GSB; $n=9$ ) permaneceram em baia de alvenaria fechada, coberta e com boa ventilação, protegidos da exposição solar durante todo o experimento. Os animais foram identificados com brinco e vermifugados com $1 \mathrm{ml} / 10 \mathrm{~kg}$ de cloridrato de levamisol 8\%, 10 dias antes do início do experimento.

0 estudo ocorreu no período de janeiro a março de 2010, no Hospital Veterinário do Centro Universitário da Grande Dourados (UNIGRAN) em Dourados-MS, totalizando 63 dias de experimento. Os dois grupos testes (grupo sol - GS e grupo sombra - GSB) receberam capim fresco cortado diariamente, proveniente de piquetes de Brachiaria decumbens. Todos os grupos receberam alimentação em cochos e foram suplementados com 200g/dia/ animal de ração comercial para ovinos, sal mineral e água ad libitum. 0 grupo GC recebeu como forragem apenas feno de capim coast-cross (Cynodon dactylon) e capim elefante (Pennisetum purpureum picado).

Amostras do capim fornecido foram colhidas antes do início do experimento e a cada 15 dias, cortadas aproximadamente a $2 \mathrm{~cm}$ da superfície do solo, em 10 locais distintos e aleatórios das pastagens. Nas amostras de capim fresco foi realizada contagem de esporos de Pithomyces chartarum (Tokarnia et al. 2007). Amostras secas da pastagem foram analisadas para protodioscina por HPLC-ESI-MS (cromatografia líquida de alta performance-electroespray-espectrofotometria de massa) por métodos descritos previamente (Lee et al. 2009), com as seguintes modificações: uma alíquota de $0,1 \mathrm{~mL}$ do extrato metanólico foi transferida para um tubo contendo $0,9 \mathrm{ml}$ de ácido fórmico a $0,1 \%$, onde foi mesclado antes da análise por HPLC-ESI-MS; e protodioscina standard (ChromaDex Irvine, CA USA) foi preparada em uma solução de ácido fórmico a 1\%:acetronila (90:10) para 
dar uma curva standard com sete pontos e uma faixa de $0,78 \mathrm{mg} /$ $\mathrm{mL}$ a $50.0 \mathrm{mg} / \mathrm{mL}$.

Foi calculada a precipitação pluviométrica acumulada 15 dias antes do experimento e nos intervalos entre as colheitas das amostras do capim, a partir dos dados registrados disponíveis junto à Embrapa para o local e período.

Diariamente os animais foram submetidos ao exame clínico para verificação das mucosas oculares e nasal, presença ou não de apatia e avaliação de alterações cutâneas compatíveis com fotossensibilização (como eritema periocular, eczema, edema de orelhas e da face) ou outros sinais de intoxicação pela gramínea.

Amostras de sangue foram colhidas duas vezes por semana por punção da veia jugular, com intervalo de três dias entre as colheitas, para mensuração das atividades séricas das enzimas aspartato aminotransferase (AST) e gama-glutamiltransferase (GGT). As mensurações foram realizadas com analisador bioquímico semi-automático (BIOPLUS ${ }^{\circledR}$ BIO-2000) e com kits comerciais (Labtest AST/GOT Liquiform e Gama GT Liquiform, Labtest Diagnóstica SA, Belo Horizonte, BR). Para comparação das atividades séricas de AST e GGT foi determinado o valor máximo de referência da população (VMRP) estudada, calculado a partir dos níveis médios pré-exposição, somado a duas vezes o desvio padrão (Stockham \& Scott 2008).

Os ovinos, que apresentaram sinais clínicos, foram imediatamente retirados do experimento para evitar o agravamento da intoxicação e submetidos à biópsia hepática (Santos Júnior 2008, Néspoli et al. 2010) ou necropsiados quando morriam. Ao final do experimento, nos animais que não adoeceram também foram realizadas biopsias hepáticas. Os fragmentos de órgãos e biópsias hepáticas foram fixados em formol tamponado $10 \%$, processados rotineiramente para inclusão em parafina, cortados a cinco micrômetros de espessura, corados com hematoxilina-eosina e analisados em microscopia de luz.

A análise estatística foi feita com o programa PrismGraph 5.0 para comparação das médias da atividade sérica enzimática de AST e GGT utilizando-se o método ANOVA e teste de Tukey. O Teste Exato de Fisher foi empregado para comparação das frequências das alterações observadas entre os grupos.

\section{RESULTADOS}

Quatro animais apresentaram sinais clínicos da intoxicação por braquiária, com a morte de três deles, correspondendo a $22,2 \%$ de morbidade e $75 \%$ de letalidade. Desse total, três ovinos mantidos em condições de exposição solar (GS) adoeceram e dois morreram. Um animal que permaneceu em baia, albergado da exposição solar (GSB), apresentou intoxicação e morreu. Não houve alterações clínicas nos ovinos do grupo controle (GC).

O surgimento dos sinais clínicos da intoxicação nos animais variou de 7 a 38 dias. Os principais sinais clínicos observados nos cordeiros que se intoxicaram são apresentados no Quadro 1. A evolução clínica da intoxicação variou de 2 a 8 dias. Nenhum animal apresentou lesões cutâneas de fotossensibilização. Os ovinos do grupo controle (GC) não demonstraram alterações clínicas durante o experimento. A frequência das alterações clínicas, morbidade e letalidade não diferiram entre os grupos GS e GSB ( $p \geq 0,05)$.

$$
\begin{aligned}
& \text { - Saponina } \\
& \text {.. PA }
\end{aligned}
$$

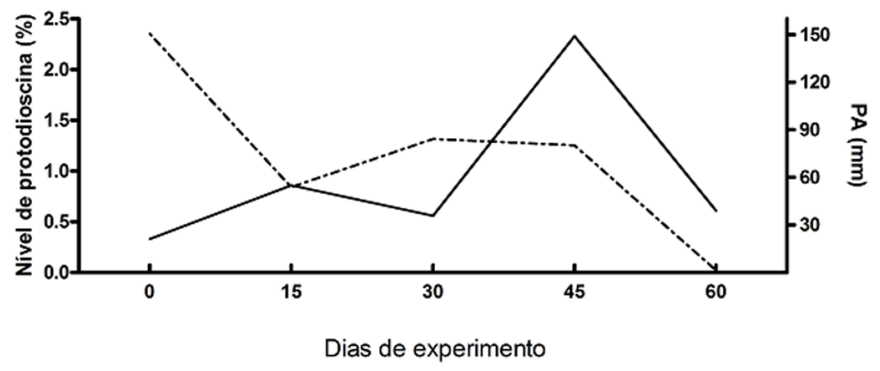

Fig.1. Níveis quinzenais de protodioscina (\%) na braquiária fornecida aos ovinos e precipitação pluviométrica acumulada (PA) durante o experimento.

Quadro 1. Principais sinais clínicos e alterações histopatológicas hepáticas em ovinos expostos ao sol (SG) e

\begin{tabular}{|c|c|c|c|c|c|c|c|c|c|c|c|c|c|c|}
\hline \multirow[t]{2}{*}{ Animal } & \multicolumn{6}{|c|}{ Sinais clínicos } & \multicolumn{8}{|c|}{ Histopatologia hepática } \\
\hline & $\overline{\mathrm{APT}}$ & EMG & FTF & SCO & HMO & ICT & TVH & $\mathrm{NIH}$ & ME & CCM & HDB & CCD & IMP & $\mathrm{B} / \mathrm{N}$ \\
\hline GS 1 & - & - & - & + & + & - & - & - & - & - & - & - & + & B \\
\hline GS 2 & - & - & - & + & + & - & - & - & - & - & - & - & + & B \\
\hline GS 3 & + & - & + & + & + & + & + & - & + & + & + & + & + & $\mathrm{N}$ \\
\hline GS 4 & - & - & - & + & + & - & - & - & - & - & - & - & - & B \\
\hline GS 5 & + & + & + & + & + & + & - & + & + & + & - & + & + & $\mathrm{N}$ \\
\hline GS 6 & - & - & - & - & + & + & + & - & + & + & + & - & - & B \\
\hline GS 7 & - & - & - & + & + & - & - & - & - & - & - & - & + & B \\
\hline GS 8 & - & - & - & + & + & - & - & - & - & - & - & - & + & B \\
\hline GS 9 & - & - & - & - & + & - & - & - & - & - & - & - & + & B \\
\hline GSB 1 & - & - & - & - & + & - & - & - & - & - & - & - & + & B \\
\hline GSB 2 & - & - & - & - & + & - & - & - & - & - & - & - & + & B \\
\hline GSB 3 & - & - & - & - & + & - & - & - & - & - & - & - & + & B \\
\hline GSB 4 & + & - & - & + & + & + & - & + & + & + & - & + & + & $\mathrm{N}$ \\
\hline GSB 5 & - & - & - & + & + & - & - & - & - & - & + & - & + & B \\
\hline GSB 6 & - & - & - & - & + & - & - & - & - & - & - & - & - & B \\
\hline GSB 7 & - & - & - & + & + & - & - & - & + & + & - & - & + & B \\
\hline GSB 8 & - & - & - & - & - & - & - & - & + & + & - & - & + & B \\
\hline GSB 9 & - & - & - & - & + & - & - & - & + & - & - & - & - & B \\
\hline
\end{tabular}
mantidos em baias (SDG) alimentados com braquiária durante o período experimental (Brasília/DF, 2012)

Sinais Clínicos: APT = apatia; EMG = emagrecimento; FTF = fotofobia; HMO = hiperemia de mucosa ocular; SCO = secreção ocular; ICT = icterícia. Histopatologia hepática: TVH = tumefação e vacuolização de hepatócitos; NIH = necrose individual de hepatócito; ME = macrófago com citoplasma espumoso; $\mathrm{CCM}$ = imagem negativa de cristais no citoplasma de macrófago; HDB = hiperplasia de ductos biliares; $\mathrm{CCD}=$ imagem negativa de cristais dentro de ductos biliares; IMP = infiltrado mononuclear periportal; $\mathrm{B} / \mathrm{N}=$ procedência do material: $\mathrm{B}$ = biópsia; $\mathrm{N}=$ necropsia. Interpretação: - ausência; + presença. 
AST

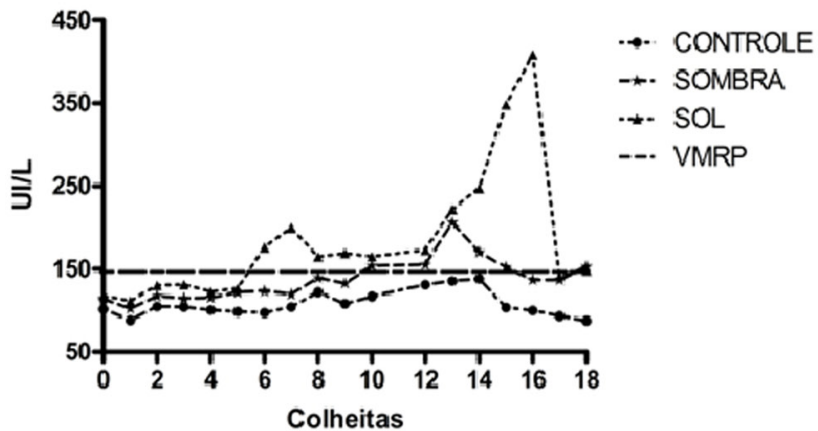

GGT

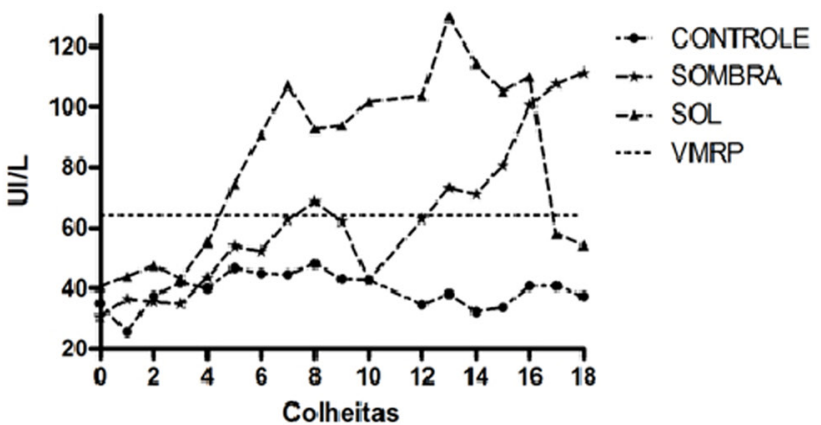

Fig.2. Atividades séricas médias de AST e GGT dos ovinos dos grupos controle (GC), sol (GS), sombra (GSB) e durante o experimento. VMRP = valor máximo de referência da população.

Durante todo o experimento não foram observados esporos do fungo Pithomyces chartarum nas colheitas da gramínea. 0 nível médio de protodioscina nas amostras de capim fornecido aos animais foi $0,94 \pm 0,80 \%$. Os resultados da mensuração desta saponina por colheita são apresentados junto à precipitação pluviométrica acumulada correspondente entre as colheitas no período do experimento (Fig.1).

Tanto os animais expostos ao sol como os mantidos na sombra apresentaram elevações das atividades séricas médias de AST e GGT (Fig.2); a elevação das atividades séricas de GGT iniciou no 7으 dia, e a de AST ao 18ํ dia após o início do experimento. 0 grupo GS apresentou atividades séricas médias da enzima AST significativamente maiores que dos grupos GSB e GC $(\mathrm{p} \leq 0,05)$. A atividade enzimática média de GGT dos ovinos alimentados com capim braquiária e expostos ao sol (grupo GS) foi maior $(\mathrm{p} \leq 0,05)$ que dos outros dois grupos (GSB e GC). Os animais alimentados com a gramínea e que permaneceram nas baias (GSB) também apresentaram níveis maiores de GGT $(\mathrm{p} \leq 0,05)$ em comparação ao grupo controle (GC).

Nos três ovinos que morreram intoxicados foram observados diferentes graus de icterícia, sendo um animal de forma acentuada (grupo GS) e dois com manifestação moderada (grupos GS e GSB). Esses animais apresentaram ainda vesícula biliar distendida e repleta, hepatomegalia com coloração amarelada difusa e padrão lobular evidente (Fig.3).

O exame histopatológico do fígado dos ovinos (Quadro 1) demonstrou tumefação, vacuolização e necrose individual de hepatócitos em 50\% dos animais doentes, e em 11,1\% do total de ovinos alimentados com braquiária. Macrófagos com imagens negativas citoplasmáticas de cristais acutiformes e citoplasma de aspecto espumoso estavam presentes no interior dos sinusoides e na região periportal respectivamente, em $38,9 \%$ e $33,3 \%$ dos grupos GS e GSB, e em $100 \%$ dos ovinos intoxicados. A hiperplasia de ductos biliares e a presença de material cristaloide refringente ocluindo a luz de ductos biliares (Fig.4) foram observados no fígado de $50 \%$ e $75 \%$ dos animais doentes respectivamente, correspondendo a $11,1 \%$ (HDB) e $16,6 \%$ (CCD) do total de ovinos que receberam braquiária. Infiltrado mononuclear periportal com predomínio de linfócitos e alguns plasmócitos foi encontrado no fígado de $75 \%$ dos ovinos intoxicados e em $77,8 \%$ do total de animais alimentados com o capim.

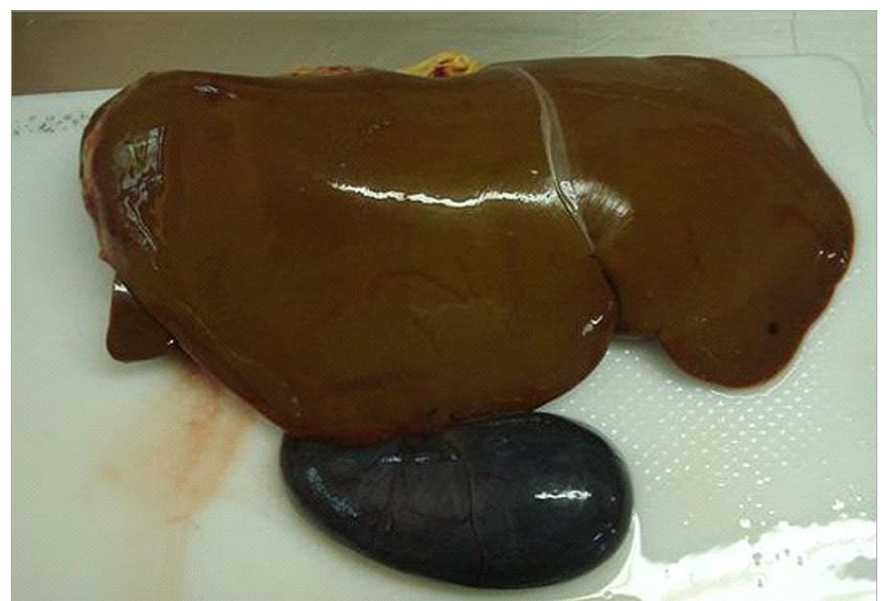

Fig.3. Fígado de ovino do grupo GS intoxicado por Bracharia spp. apresentando hepatomegalia, coloração amarelada e vesícula biliar acentuadamente distendida.

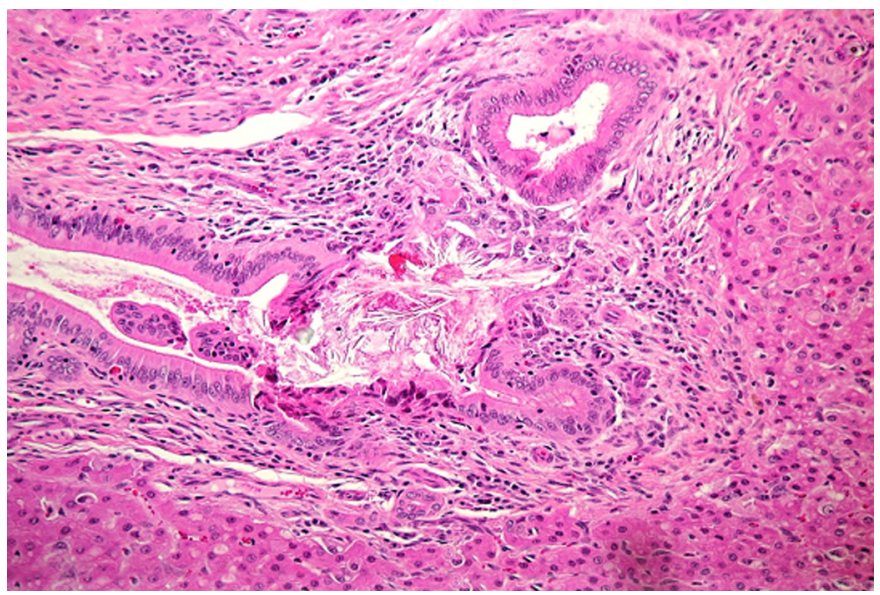

Fig.4. Descamação do epitélio biliar, imagem negativa de cristais ocluindo a luz de ducto biliar e infiltrado inflamatório mononuclear adjacente, no fígado de ovino do grupo GS intoxicado por Bracharia spp. HE, obj.40x. Barra: $50 \mu \mathrm{m}$.

Esta alteração também foi observada no fígado de $62 \%$ dos ovinos do grupo controle, sendo o único achado histopatológico nesses animais. As frequências de manifestação das principais alterações patológicas hepáticas, mesmo não ocorrendo no grupo controle, não apresentaram diferenças significativas entre todos os grupos de ovinos $(\mathrm{p} \geq 0,05)$. 


\section{DISCUSSÃO}

Muitos aspectos clínico-epidemiológicos e mecanismos de intoxicação pela braquiária ainda permanecem desconhecidos. Até o momento, os sinais de fotossensibilização, envolvendo especialmente a pele, como eritema, descamação, eczema, edema facial e periocular, são apontados como condição central para o diagnóstico da intoxicação pela gramínea (Lemos et al. 1996, Mendonça et al. 2008, Santos et al. 2008, Mustafa et al. 2012). Do ponto de vista toxicológico, a forrageira é frequentemente classificada como planta tóxica fotossensibilizante (Tokarnia et al. 2012, Riet-Correa \& Méndez 2007). No presente experimento foi reproduzida experimentalmente a intoxicação por Brachiaria decumbens, inclusive com a morte de ovinos, na ausência de sinais clínicos de dermatite por fotossensibilização, tanto nos animais que permaneceram na sombra quanto nos que permaneceram no sol. A intoxicação e morte de um dos ovinos protegidos da exposição solar (GSB) demonstra que o efeito tóxico da gramínea acontece independente do animal estar exposto ou não ao sol, portanto, não necessariamente associado ao fenômeno de fotossensibilização. Experimentalmente, é frequente a morte de ovinos não-adaptados ao pastejo em piquetes de Brachiaria spp., com as formas hiperagudas e agudas da intoxicação por braquiária, e sem a presença de sinais de fotossensibilização (Santos Júnior 2008, Castro et al. 2011). Por outro lado, as maiores atividades séricas de AST e GGT no grupo exposto ao sol, quando comparadas ao grupo que permaneceu na sombra, sugerem que a exposição solar não determina a ocorrência de sinais clínicos da intoxicação, mas exacerba o quadro clínico. No entanto, o número de animais doentes do grupo exposto ao sol (3/9) em relação ao grupo que permaneceu na sombra (1/9) não permitiu discriminar claramente essa tendência $(\mathrm{p} \geq 0,05)$.

Os ovinos alimentados ao cocho com braquiária, apesar das condições experimentais, apresentaram taxas de morbidade e de letalidade semelhantes às observadas em ovinos intoxicados naturalmente pela gramínea no Rio Grande do Norte, no Mato Grosso do Sul e no Brasil Central (Silva et al. 2006, Brum et al. 2007, Mustafa et al. 2012). Essas observações demonstram que a alimentação ao cocho com braquiária fresca pode ser utilizada para estudos experimentais com ovinos jovens não-adaptados, devido à grande susceptibilidade desses animais à intoxicação por braquiária (Khairi et al. 2000, Castro et al. 2011).

O tempo para surgimento dos sinais clínicos da intoxicação nos animais foi semelhante ao encontrado em outros ovinos experimentalmente intoxicados por braquiária (Santos Júnior 2008, Saturnino et al. 2010). Essa grande variação de tempo, independente da situação, pode ser atribuída a diversos fatores, entre eles a diferença na susceptibilidade/resistência dos animais, a variação na toxicidade da gramínea, ou outros fatores ainda desconhecidos (Castro et al. 2011).

Hiperemia, secreção mucóide bilateral na mucosa ocular e icterícia foram sinais clínicos presentes em todos os animais que adoeceram e são descritos com frequência em intoxicações naturais e experimentais de ovinos por braquiária (Khairi et al. 2000, Santos Júnior 2008, Castro et al. 2011, Mustafa et al. 2012). A fotofobia foi observada somente nos animais intoxicados do grupo que permaneceu no sol. A patogênese dessas alterações ainda não é conhecida, mas suspeita-se estar relacionada ao aumento da sensibilidade do local à radiação solar por deposição da filoeritrina (Tokarnia et al. 2012, Lemos \& Purisco 2002, Santos Júnior 2008). Entretanto, hiperemia e secreção ocular também foram observadas em vários cordeiros dos grupos GS e GSB sem outros sinais clínicos, e possivelmente não são decorrentes à fotossensibilidade. A apatia e o emagrecimento são sinais clínicos frequentemente observados em animais introduzidos em pastagens de braquiária e intoxicados por esta gramínea (Graydon et al. 1991, Tokarnia 2000, Cruz et al. 2001, Lemos \& Purisco 2002, Castro et al. 2011, Riet-Correa et al 2011). Essas alterações ocorreram nos três animais que morreram e possivelmente estão relacionadas com a lesão hepática produzida pela ingestão da gramínea. É provável que o emagrecimento ocorra em consequência da apatia e anorexia ou por alguma interferência no metabolismo hepático.

No presente estudo, nenhum animal apresentou lesões de pele como eritema, edema de face e orelhas, queda de pêlos, erosões e ulcerações cutâneas, que caracterizam a fotossensibilização hepatógena por retenção hepática da filoeritrina em ruminantes (Stegelmeier 2002, Pimentel et al. 2007) e são descritas em ovinos intoxicados por Brachiaria spp. (Lemos et al. 1996, Cruz et al. 2001, Mendonça et al. 2008, Santos et al. 2008). A ausência de lesões cutâneas por fotossensibilização ocorre experimentalmente em ovinos não-adaptados ao pastejo na gramínea, que morreram intoxicados por braquiária, possivelmente justificada pela grande susceptibilidade desses animais (Castro et al. 2007, Santos Júnior 2008, Castro et al. 2011).

Nos ovinos necropsiados, os achados mais importantes foram icterícia generalizada, hepatomegalia com distensão da vesícula biliar e o fígado de coloração amarelada. A icterícia observada no exame clínico e necropsia refletem a lesão hepatóxica produzida pela ingestão de braquiária, confirmada pelos aumentos das atividades séricas de AST e GGT. 0 principal mecanismo apontado para o surgimento destas alterações é o extravasamento de pigmentos biliares oriundos da obstrução dos ductos biliares por cristais formados pela conjugação da saponina com cálcio (Cheeke 1995, Driemeier et al. 1998, Lemos et al. 1998, Santos et al. 2008, Riet-Correa et al. 2011).

As alterações histopatológicas dos animais necropsiados e das biópsias hepáticas observadas nesse estudo são semelhantes às descrições anteriores de ovinos intoxicados por braquiária (Graydon et al. 1991, Lemos et al. 1996, Driemeier et al. 1998, Cruz et al. 2000, Tokarnia et al. 2012, Castro et al. 2007, Santos Junior. 2008, Saturnino et al. 2010). Macrófagos com citoplasma espumoso, imagens negativas de cristais intracitoplasmáticos em macrófagos na região periportal e nos sinusóides hepáticos e cristais dentro de ductos biliares foram os achados histopatológicos mais relevantes observados nos animais dos grupos GS e GSB. Essas alterações histológicas estão entre as mais consistentes, que refletem a ação hepatotóxica de plantas que contém saponinas esteroidais litogênicas como Brachiaria 
decumbens e Tribulus terrestris (Smith \& Miles 1993, Cruz et al. 2000, Aslani et al. 2003). Tumefação e vacuolização hepatocelular, necrose individual de hepatócitos e hiperplasia de ductos biliares foram achados microscópicos menos frequentes nos ovinos intoxicados. A hiperplasia ductal é considerada uma resposta comum a diversas hepatopatias e seu mecanismo ainda é desconhecido (Cullen 2009). A necrose e tumefação de hepatócitos periportais podem ocorrer na intoxicação de ovinos por braquiária e são atribuídas a presença dos cristais insolúveis de saponinas (Santos et al. 2008).

Os níveis de protodioscina (saponina) na forrageira durante todo o experimento foram capazes de causar intoxicação e morte dos ovinos. Até o momento, existem poucas descrições dos níveis de protodioscina nas pastagens associados à intoxicação de ovinos. Em condições experimentais foi observada flutuações nos valores de saponina $(0,52$ a $1,06 \%$ ) em piquetes de $B$. decumbens durante o período da seca, porém suficientes para intoxicar a maioria dos animais não adaptados ao pastejo na gramínea (Castro et al. 2007). Em surtos naturais de intoxicação de ovinos pelo capim também foram observadas amplitudes ainda maiores nos valores de protodioscina $(0,30$ a $2,56 \%)$ nas pastagens avaliadas (Mustafa et al. 2012). As variações observadas no presente experimento, ainda maiores do que em outros relatos, podem ser atribuídas às flutuações dos valores da toxina na planta (Barbosa-Ferreira et al. 2011, Castro et al. 2011). Foi demonstrado que a planta em brotação contem maiores concentrações de saponinas (Castro et al. 2011, Barbosa-Ferreira et al. 2011), no entanto a ocorrência de surtos em todas as épocas do ano, tanto em bovinos (Souza et al. 2010) quanto em ovinos (Mustafa et al. 2012), sugere que outros fatores ainda desconhecidos influem na concentração de saponinas nas pastagens de Brachiaria spp. A ausência de esporos de $P$. chartarum em todas as amostras de capim coletadas é semelhante ao encontrado nas pastagens utilizadas para ovinos no Brasil-Central (Castro et al. 2011, Mustafa et al. 2012).

As observações do presente experimento demonstram a importância da hepatotoxicidade da gramínea na intoxicação dos ovinos, independentemente da exposição dos animais ao sol e na ausência de fotossensibilização. Esses achados abrem uma nova perspectiva para elucidar sua patogenia, e para a necessidade de melhor compreendê-la, visando estabelecer novas estratégias de controle e prevenção. Os resultados apontam para a necessidade de conscientizar produtores e técnicos para a morte de animais e redução na produtividade dos rebanhos de ovinos mantidos em pastagens da gramínea mesmo na ausência de fotossensibilização. Os sinais considerados clássicos da intoxicação nem sempre ocorrem, sendo o diagnóstico muitas vezes confirmado apenas pelo exame histopatológico hepático em conjunto às alterações dos níveis de AST e GGT.

Agradecimentos.- Ao Conselho Nacional de Pesquisa (CNPq) pelo suporte financeiro. Projeto financiado pelo Instituto de Ciência e Tecnologia para o Controle das Intoxicações por Plantas (Proc. CNPq 573534/20080) e Bolsa Produtividade (Proc. CNPq 308700/2009-0). À Coordenação de Aperfeiçoamento de Pessoal de Nível Superior (CAPES), pela concessão de bolsa de mestrado. À professora Fabiana Satake e aos alunos Fernando Wagner Cabral, Matheus Alves Cornacioni e Jéssica dos Santos pelo auxílio técnico no desenvolvimento do experimento.

\section{REFERÊNCIAS}

Abdullah A.S., Lajis N.H., Bremner J.B., Davies N.W., Mustapha W. \& Rajion M.A. 1992. Hepatotoxic constituents in the rumen of Brachiaria decumbens intoxicated sheep. Vet. Hum. Toxicol. 34:154-155.

Aslani M.R., Movassaghi A.R., Mohri M., Pedram M. \& Abavisani A. 2003. Experimental Tribulus terrestris poisoning in sheep: clinical, laboratory and pathological findings. Vet. Res. Commun. 27(1):53-62.

Barbosa-Ferreira M., Brum K.B., Fernandes C.E.S., Martins C.F., Monteiro L.C., Rezende K.G., Riet-Correa F., Haraguchi M., Wysocki Junior H.L. \& Lemos R.A.A. 2011. Variations of saponin level $\mathrm{x}$ maturation in Brachiaria brizantha leaves, p.118-123. In: Riet-Correa F., Pfister J., Schild A.L. \& Wierenga T. (Eds), Poisoning by Plants, Mycotoxins and related Toxins. CAB International, London.

Brum K.B., Haraguchi M., Lemos R.A.A., Riet-Correa F. \& Fioravanti M.C.S. 2007. Crystal-associated cholangiopathy in sheep grazing Brachiaria decumbens containing the saponin protodioscin. Pesq. Vet. Bras. 27:39-42.

Castro M.B., Moscardini A.R.C., Reckziegel G.C., Novaes E.P.F., Mustafa V.S., Paludo G.R., Borges J.R.J. \& Riet-Correa F. 2007. Susceptibilidade de ovinos a intoxicação por Brachiaria decumbens. Anais V Congreso Latinoamericano de Especialistas en Pequeños Ruminantes y Camélidos Sudamericanos, Buenos Aires, p.57-59.

Castro M.B., Santos Jr. H.L., Mustafa V.S., Gracindo C.V., Moscardini A.C.R., Louvandini H., Paludo G.R., Borges J.R.J., Haraguchi M., Ferreira M.B. \& Riet-Correa F. 2011. Brachiaria spp. poisoning in sheep in Brazil. Experimental and epidemiological findings, p.110-117. In: Riet-Correa F., Pfister J., Schild A.L. \& Wierenga T. (Eds), Poisoning by Plants, Mycotoxins and related Toxins. CAB International, London.

Cheeke P.R. 1995. Endogenous toxins and mycotoxins in forage grasses and their effects on livestock. J. Anim. Sci. 3:909-918.

Cruz C., Driemeier D., Pires V.S., Colodel E.M., Taketa A.T.C. \& Schenkel E. 2000. Isolation of steroidal sapogenins implicated in experimentally induced cholangiopathy of sheep grazing Brachiaria decumbens in Brazil. Vet. Hum. Toxicol. 42:142-145.

Cruz C., Driemeier D., Pires V.S. \& Schenkel E.P. 2001. Experimentally induced cholangiohepatopathy by dosing sheep with fractionated extracts from Brachiaria decumbens. J. Vet. Diagn. Invest. 13(2):170-172.

Cullen J.F. 2009. Fígado, sistema biliar e pâncreas, p.393-461. In: McGavin M.D. \& Zachary J.F. (Eds), Bases da Patologia em Veterinária. 4ª ed. Elsevier, Rio de Janeiro.

Driemeier D., Barros S.S., Peixoto P.V., Tokarnia C.H., Döbereiner J. \& Brito M.F. 1998. Estudo histológico, histoquímico e ultra-estrutural de fígados e linfonodos de bovinos com presença de macrófagos espumosos ("foam cells"). Pesq. Vet. Bras. 18:29-34.

Graydon R.I., Hamid H. \& Zahari P. 1991. Photosensitization and crystal associated cholangiohepatopathy in sheep grazing Brachiaria decumbens. Aust. Vet. J. 68:234-236.

Khairi H.M., Elsheikh H.A. \& Abdullah A.S. 2000. The effect of signal grass (Brachiaria decumbens) on drug-metabolizing enzymes in sheep and comparison with normal cells. Vet. Hum. Toxicol. 42:193-195.

Lajis N.H., Abdullah S.A., Salim J.S., Bremmer J.B. \& Khan M.N. 1993. Epi-sarsasapogenin and epi-smilagenin isolated from the rumen content of sheep intoxicated by Brachiaria decumbens. Steroids 58:387-389.

Lee S.T., Mitchell R.B., Wang Z., Heiss C., Gardner D.R., Azadi P. 2009. Isolation, characterization and quantification of steroidal saponins in switchgrass (Panicum virgatum L.). J. Agric. Food Chem. 57:2599-2604.

Lemos R.A.A., Ferreira L.C.L., Silva S.M., Nakazato L. \& Salvador S.C. 1996. Fotossensibilização e colangiopatia associada a cristais em ovinos em pastagem com Brachiaria decumbens. Ciência Rural 26:109-113.

Lemos R.A.A., Oliveira V.A., Herrero Jr G.O., Silveira A.C. \& Porfírio L.C. 1998. Fotossensibilização e colangiopatia associada a cristais em caprinos mantidos sob pastagens de Brachiaria decumbens no Mato Grosso do Sul. Ciência Rural 28:507-510. 
Lemos R.A.A. \& Purisco E. 2002. Plantas que causam fotossensibilização hepatógena, p.292 In: Lemos R.A.A., Barros N. \& Brum K.B. (Eds), Enfermidades de Interesse Econômico em Bovinos de Corte: perguntas e respostas. UFSM, Campo Grande, MS.

Mendonça F.S., Camargo L.M., Freitas S.H., Dória R.G.S., Baratella-Evêncio L. \& Evêncio Neto J. 2008. Aspectos clínicos e patológicos de um surto de fotossensibilização hepatógena em ovinos pela ingestão de Brachiaria decumbens (Gramineae) no município de Cuiabá, Mato Grosso. Ciênc. Anim. Bras. 9(4):1034-1041.

Mustafa V.S., Moscardini A.R.C., Borges J.R., Reckziegel G.C., Riet-Correa F. \& Castro M.B. 2012. Caracterização da intoxicação natural por Brachiaria spp em ovinos no Brasil Central. Pesq. Vet. Bras. 32(12):1272-1280.

Néspoli P.B., Gheller V.A., Peixoto P.V., França T.N., Carvalho A.U., Araújo D.K.G. \& Malm C. 2010. Avaliação de técnicas de biópsia hepática em ovinos. Pesq. Vet. Bras. 30(1):29-36.

Pimentel L.A., Riet-Correa F., Guedes K.M.R., Macedo J.T.S.A., Medeiros R.M.T. \& Dantas A.F.M. 2007. Fotossensibilização primária em equídeos e ruminantes no semi-árido causada por Froelichia humboldtiana (Amaranthaceae). Pesq. Vet. Bras. 27:23-28.

Riet-Correa B., Castro M.B., Lemos R.A.A., Riet-Correa G., Mustafa V.S. \& Riet-Correa F. 2011. Brachiaria spp. poisoning of ruminants in Brazil. Pesq. Vet. Bras. 31(3):183-192.

Riet-Correa F. \& Méndez M.D.C. 2007. Intoxicações por plantas tóxicas e micotoxinas, p.99-221. In: Riet-Correa F., Schild A.L., Lemos R.A.A., Borges J.R.J. (Eds), Doenças de Ruminantes e Equídeos. Vol.2. 3ª ed. Pallotti Editora, Santa Maria.

Santos J.C.A., Riet-Correa F., Simões S.V. \& Barros C.S.L. 2008. Patogênese, sinais clínicos e patologia das doenças causadas por plantas hepatotóxicas em ruminantes e eqüinos no Brasil. Pesq.Vet. Bras. 28(1):1-14.

Santos Júnior H.L. 2008. Estudo da toxicidade de diferentes estágios de crescimento de Brachiaria decumbens em ovinos. Dissertação de Mestrado em Saúde Animal, Faculdade de Agronomia e Medicina Veterinária, Universidade de Brasília, Brasília, DF. 70p.

Saturnino K.C., Mariani T.M., Barbosa-Ferreira M., Brum K.B., Fernandes C.E.S. \& Lemos R.A.A. 2010. Intoxicação experimental por Brachiaria decumbens em ovinos confinados. Pesq. Vet. Bras. 30(3):195-202.

Souza R.I.C., Riet-Correa F., Barbosa-Ferreira M., Brum K.B., Fernandes C.E. \& Lemos R.A.A. 2010. Intoxicação por Brachiaria spp. em bovinos no Mato Grosso do Sul. Pesq. Vet. Bras. 30(12):1036-1042.

Stockham S.L. \& Scott M.A. 2008. Fundamental of Veterinary Clinical Pathology. $2^{\text {nd }}$ ed. Blackwell Publishing, Iowa, p.16-17.

Silva D.M., Riet-Correa F., Medeiros R.M.T. \& Oliveira O.F. 2006. Plantas tóxicas para ruminantes e eqüídeos no Seridó Ocidental e Oriental do Rio Grande do Norte. Pesq. Vet. Bras. 26(4):223-236.

Smith B.L. \& Miles C.O. 1993. A letter to the editor: a role for Brachiaria decumbens in heoatogenous photosensitization of ruminants? Vet. Hum. Toxicol. 35(3):256-257.

Stegelmeier B.L. 2002. Equine photosensitization. Clin. Tech. Eq. Pract. 2:81-88.

Tokarnia C.H., Döbereiner J. \& Silva M.F. 2007. Plantas tóxicas da Amazônia: a bovinos e outros herbívoros. Editora INPA, Manaus, AM. 97p.

Tokarnia C.H., Döbereiner J. \& Peixoto P.V. 2012. Plantas Tóxicas do Brasil. Editora Helianthus, Rio de Janeiro. 566p. 